\title{
Implementasi Pendekatan Personal Learning Environtments (PLE) dalam Praktikum Fisika
}

\author{
Paramita Ayuningtyas $^{\text {a) }}$, Dwi Sulisworo ${ }^{\text {b) }}$ \\ Magister Pendidikan Fisika, Universitas Ahmad Dahlan, Yogyakarta \\ Kampus II, Jalan Pramuka 42, Yogyakarta \\ Email: a)mitaparara22@gmail.com, ${ }^{\text {b) }}$ sulisworo@gmail.com
}

\begin{abstract}
The background of this quasy experimental research is the lack of students' independency in carrying out experiments, the low integration of information technology to explore student ability, also PLE approach that has not been widely implemented in learning. The purpose of this research, which is implemented PLE approach in the physics experiment to increase: independent and experiment abilities also the skill to make experiment report of high school student. The research was conducted from April until May 2015 at senior high school at Yogyakarta. The results of the research show that implementation PLE in the experiment: affect students in the determine the converging lens focus; in adjust theory and experimental purpose; and to conclude the experimental process and report.
\end{abstract}

Keywords: Personal Learning Environtments, physics experiment, independent.

\begin{abstract}
Abstrak
Penelitian eksperimen ini dilatarbelakangi kekurang mandirian siswa berpraktikum, kurang maksimalnya peran teknologi informasi untuk menggali potensi siswa, serta pendekatan PLE yang belum banyak diimplementasikan di pembelajaran. Sedangkan tujuan penelitian ini yaitu mengimplementasikan pendekatan PLE pada praktikum fisika untuk meningkatkan kemandirian, kemampuan praktikum serta keterampilan membuat laporan praktikum fisika pada siswa SMA. Penelitian dilakukan bulan April hingga Mei 2015 di SMA Negeri 3 Yogyakarta. Hasil penelitian menunjukkan implementasi PLE dalam praktikum: mempengaruhi kemampuan siswa menentukan fokus lensa cembung; menghubungkan dasar teori dengan tujuan praktikum; dan menyimpulkan hasil praktikum (proses maupun laporan).
\end{abstract}

Kata-kata Kunci: Personal Learning Environtments, praktikum fisika, kemandirian.

\section{PENDAHULUAN}

Fisika merupakan keilmuan yang sangat dekat dengan kehidupan sehari-hari, dan menggunakan kegiatan praktikum sebagai sarana untuk memudahkan siswa memahami materi. Namun justru kebanyakan siswa tidak memahami korelasi antara praktikum yang dilakukan dengan materi, siswa menjadi kurang mandiri dan kurang mampu berpraktikum hingga berimbas pada pembuatan laporan praktikum. Oleh karenanya dibutuhkan rancangan praktikum fisika yang dapat meningkatkan kemandirian, kemampuan praktikum, serta kemampuan menyusun laporan praktikum.

PLE dapat digunakan sebagai pendekatan yang menghargai kemampuan siswa secara personal. Dalam pendekatan ini, semua siswa mendapatkan kesempatan untuk melakukan pembelajaran sesuai dengan kecepatan menyerap keilmuan. Dan internet merupakan fasilitas penunjang yang sangat 
dibutuhkan dalam impelmentasi pendekatan PLE, mengingat kemampuannya untuk melakukan akses keilmuan yang sangat luas dan dan mudah didapatkan. Maka diharapkan pendekatan PLE dengan ditunjang oleh internet dapat digunakan untuk merancang sebuah praktikum yang diharapkan mampu meningkatkan kemandirian, kemampuan berpraktikum, serta kemampuan membuat laporan praktikum.

Dicke (2010) menyatakan bahwa PLE adalah sebuah pendekatan atau cara pandang e-learning dilihat dari sudut pandang pengalaman belajar mandiri siswa/pengguna yang melihat e-learning sebagai aktivitas yang biasa dilakukan seseorang ketika online, tools-nya bebas, bisa dengan social networking, blog atau tools lainnya. Setiap saat ketika online, belajar sesuatu melalui search engine, social networking, weblog, dan lain-lain itulah yang disebut sebagai PLE.

Skrabut menjelaskan tentang PLE utamanya merupakan skema pengaturan berdasarkan komputer untuk pembelajaran yang diatur oleh diri sendiri. Istilah PLE menggambarkan alat, komunitas, dan layanan yang membuat individu pebelajar untuk memimpin dirinya sendiri belajar dan mengejar tujuan pendidikan. Sehingga pembelajaran saat ini bukan lagi terbatas pada proses penyampaian berita kepada siapapun .

PLE secara relatif merupakan sebuah fenomena yang baru dalam domain e-learning. Penggunaanya dimotivasi oleh beberapa hal berikut, yaitu: (a) kebutuhan life long learners untuk sebuah sistem yang menyediakan interface standard system e-learning untuk institusi berbeda yang mengijinkan pertukaran informasi portofolio, (b) respon pendekatan pedagogik yang mengharuskan untuk belajar dengan e-learning berada di bawah kontrol pebelajar itu sendiri, (c) kebutuhan pebelajar yang terkadang melakukan aktivitas belajar offline (Mark 2006).

PLE mempunyai beberapa manfaat daripada sistem manajemen pembelajaran tradisional. PLE secara alami dibuat untuk pebelajar yang berpusat pada lingkungan, karena pebelajar mengontrol seluruh lingkungan. PLE secara bersamaan membawa bermacam-macam lingkungan kerja, belajar, dan bermain. Lingkungan belajar adalah berbagai lokasi fisik, konteks dan budaya di mana peserta didik belajar.

Praktikum merupakan salah satu kegiatan yang sesuai dalam pendekatan saintifik yang diterapkan oleh kurikulum 2013. Dalam sebuah rangkaian praktikum, selain melakukan percobaan, tentunya diperlukan kegiatan lain untuk mengkomunikasikan hasil praktikum agar dapat diketahui oleh orang lain atau publik di luar praktikan, yaitu dengan penulisan laporan praktikum. Mauliyani (2014) menyatakan bahwa laporan praktikum merupakan hasil kerja praktikum yang ditulis dalam bentuk laporan. Harry Firman dalam Mauliyani (2014) menyatakan bahwa sebuah laporan praktikum yang lengkap terdiri atas komponen-komponen seperti tujuan, teori, alat dan bahan, prosedur percobaan, hasil pengamatan, pembahasan, dan kesimpulan.

Cara kerja lensa didasari oleh teori pembiasan cahaya. Giambattista (2010) menyatakan bahwa saat cahaya lewat dari satu medium transparent ke medium lain, maka panjang gelombang akan berubah (kecuali kecepatan cahaya dalam dua media adalah sama) jika frekuensi tetap. Tambahan, prinsip Huygens membantu memahami mengapa seakan terjadi perubahan arah sinar saat melewati batasan di antara dua media, fenomena inilah yang disebut refraksi

Halliday (2010) menjelaskan lensa merupakan objek tembus pandang dengan dua permukaan pembias yang memiliki sumbu utama berhimpit. Ketika sebuah lensa dikeliling udara, sinar membias dari udara ke lensa, menembus lensa, dan kemudian dibiaskan kembali ke udara. Setiap pembiasan dapat mengubah arah perjalanan.

Young (2010) menyebutkan bahwa refraksi pada permukaan bola adalah sebuah antarmuka bola di antara dua material optis dengan indeks refraksi yang berbeda.Berdasarkan apa yang terjadi pada sinar saat melewati lensa, lensa dapat diklasifikasikan menjadi divergen dan konvergen. Dalam penelitian ini yang akan dibicarakan lebih spesifik adalah lensa tipis, yaitu lensa yang bagian paling tebalnya relatif tipis dibandingkan jarak objek, jarak bayangan, dan jari-jari kelengkungan dari dua permukaan lensa.

Setiap lensa mempunyi dua titik fokus. Jarak antara setiap titik fokus dan pusat optik merupakan panjang fokus lensa. Hanya dibutuhkan dua sinar untuk menggambar tempat pembentukan bayangan pada lensa tipis, sinar ketiga untuk memastikan. Ketiga sinar itu disebut sinar utama. Sinar utama yang ketiga digunakan membuat titik fokus kedua yang berada di sisi berlawanan dari titik fokus utama. Dari segitiga EGC dan DBC yang mirip, didapatkan: 


$$
\tan \alpha=\frac{h}{p}=\frac{-h^{\prime}}{q}
$$

Untuk gambar yang terbalik, $h$ ' bernilai negatif, $-h$ sama dengan BD. Sehingga persamaan perbesaran lensa:

$$
m=\frac{h^{\prime}}{h}=-\frac{q}{p}
$$

Dari dua segitiga lain yaitu ACF dan DBF, didapatkan :

$$
\begin{aligned}
& \tan \beta=\frac{h}{f}=\frac{-h}{q-f} \\
& \frac{q-f}{f}=\frac{-h^{\prime}}{h}=\frac{q}{p}
\end{aligned}
$$

Jika semuanya dibagi $q$, maka didapatkan persamaan :

$$
\frac{1}{p}+\frac{1}{q}=\frac{1}{f}
$$

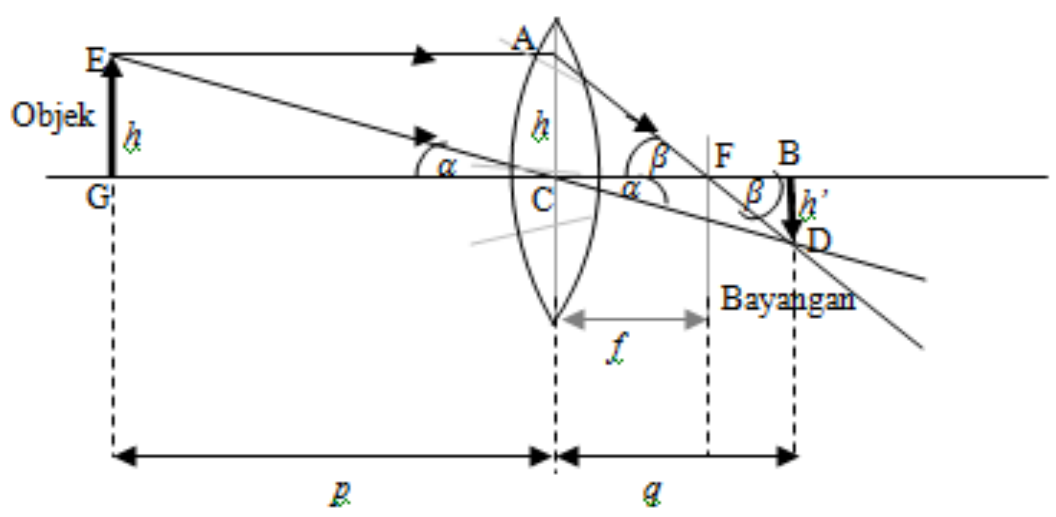

GAMBAR 1. Diagram sinar untuk menentukan perbesaran pada lensa tipis.

\section{METODE PENELITIAN}

Penelitian ini merupakan penelitian eksperimen yang dilaksanakan di SMA N 3 Yogyakarta pada bulan April hingga Mei 2015. Berdasarkan uji normalitas dan homogenitas, dipilih kelas X MIA 4 sebagai kelas eksperimen yang diberi perlakuan praktikum dengan pendekatan PLE, dan kelas X MIA 6 sebagai kelas kontrol yang diberi perlakuan praktikum biasa. Materi yang dipilih adalah praktikum lensa cembung.

Terdapat enam variabel yang dibahas, yaitu pendekatan PLE dalam praktikum fisika (variabel bebas), kemampuan dan kemandirian siswa melaksanakan praktikum fisika, keterampilan membuat laporan praktikum (variabel terikat), serta guru, materi pelajaran, dan jumlah jam pelajaran (variabel kontrol).

Pengumpulan data dalam penelitian ini dibagi dalam pre test dan post test. Data juga didapatkan dari angket dan hasil penilaian laporan praktikum yang mengacu pada rubrik. Pengujian hipotesis dilakukan dengan uji one way anova dalam program SPSS 16 yaitu untuk mengetahui signifikansi beda rata-rata dua kelompok. Dengan demikian akan diketahui ada tidaknya perbedaan antara kelas kontrol dan eksperimen setelah diberi perlakuan. Terdapat dua jenis hipotesis yang diuji, yaitu kemandirian dan kemampuan siswa berpraktikum ( 8 hipotesis), serta kemampuan siswa membuat laporan praktikum (4 hipotesis).

Angket digunakan untuk menganalisis pendapat siswa. Angket yang diberikan ada dua, yaitu tentang praktikum fisika dan tentang pemanfaatan internet untuk pembelajaran. Hasil angket dianalisis menggunakan program Microsoft Excel. 


\title{
HASIL DAN PEMBAHASAN
}

\begin{abstract}
Angket
Hasil analisis angket mengenai praktikum fisika: (1) praktikum fisika bermanfaat untuk memudahkan penguasaan konsep materi yang sedang dipelajari, (2) siswa tidak mengalami kesulitan memahami tujuan praktikum, (3) diskusi setelah praktikum cukup membantu penguasaan konsep materi yang dipelajari, (4) saat diskusi diperlukan banyak bantuan dari guru untuk memahami hal-hal yang didiskusikan, (5) menurut siswa membuat kesimpulan hasil diskusi tidak sulit dilakukan, (6) siswa merasa tidak perlu banyak bantuan dari guru untuk dapat menyimpulkan hasil percobaan, (7) presentasi kelompok yang biasa dilakukan dalam pembelajaran menurut siswa bermanfaat untuk membantu memahami konsep materi yang sedang dipelajari, (8) siswa kurang antusias untuk mempresentasikan hasil praktikum. (9) siswa mengharapkan tiap kelompok diberikan kebebasan merancang dan melakukan praktikum sendiri dengan bahan yang disediakan sendiri, (10) internet sangat membantu siswa mengumpulkan teori bahan praktikum.
\end{abstract}

\section{Praktikum}

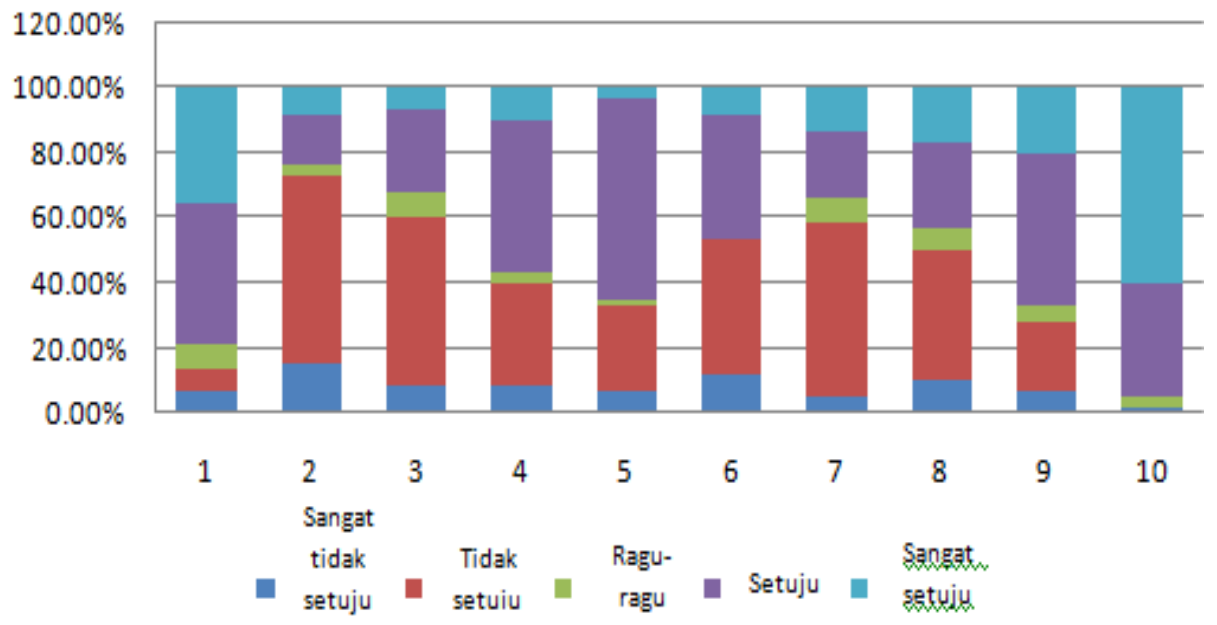

GAMBAR 2. Grafik hasil angket praktikum fisika.

\section{Pembelajaran}

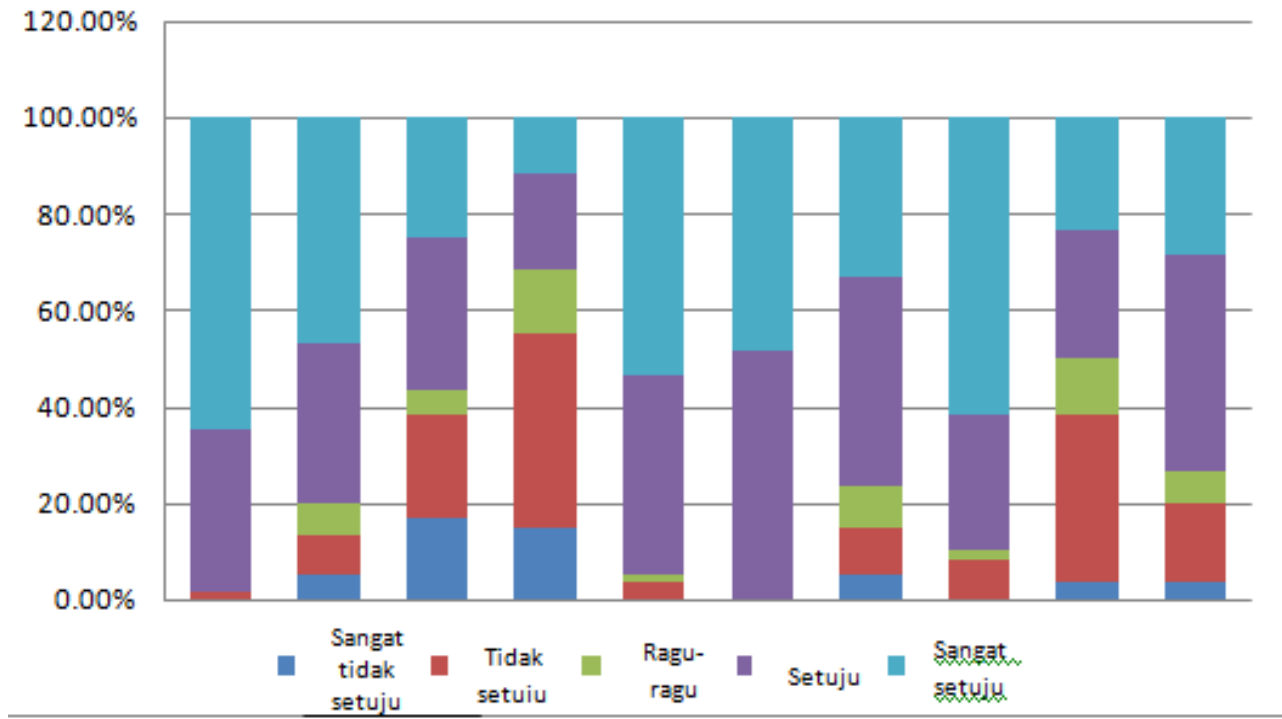

GAMBAR 3. Grafik hasil angket pemanfaatan internet untuk pembelajaran. 
Hasil analisis angket pemanfaatan internet dalam pembelajaran: (1) siswa dapat menggunakan internet untuk menemukan informasi penunjang pembelajaran, (2) siswa sudah terbiasa menggunakan social media seperti facebook, twitter, instagram, dan sebagainya, (3) kebanyakan siswa mempunyai blog pribadi, (4) siswa belum memanfaatkan blog pribadi untuk keperluan pembelajaran, (5) siswa mampu mengoptimalkan penggunaan Google Search Engine, (6) siswa dapat menggunakan Google Application, (7) siswa dapat menggunakan software pembelajaran tertentu untuk menunjang penguasaan materi, (8) internet banyak membantu siswa untuk menguasai materi pembelajaran, (9) siswa lebih senang saat harus banyak mencari sendiri materi pembelajaran yang dipelajari, (10) belajar mandiri membuat kemampuan siswa lebih berkembang.

\section{Uji Hipotesis}

Uji hipotesis menggunakan uji one way anova dari program SPSS 16, di mana jika sig > 0,05 tidak terdapat perbvedaan secara signifikan, tapi jika sig $<0,05$ maka terdapat perbedaan signifikan. Pertama mengenai kemandirian dan kemampuan siswa melaksanakan praktikum fisika yang dijabarkan dalam delapan hipotesis. Hasil ujinya adalah sebagai berikut: (1) sig 0,171, kemampuan merangkai alat praktikum antara kelas kontrol dan eksperimen tidak berbeda signifikan; (2) sig 0,005, kemampuan menghitung (menentukan) fokus lensa cembung antara kelas kontrol dan eksperimen berbeda signifikan, rerata kelas eksperimen 1,833 sedangkan kelas kontrol 1,400; (3) sig 0,414, kemampuan mengenali alat praktikum fisika antara kelas kontrol dan eksperimen tidak berbeda signifikan; (4) sig 0,121, kemampuan menuliskan tujuan praktikum antara kelas kontrol dan eksperimen tidak berbeda signifikan; (5) sig 0,283, kemampuan menuliskan dasar teori penunjang antara kelas kontrol dan eksperimen tidak berbeda signifikan; (6) sig 0,009, kemampuan menyesuaikan dasar teori penunjang dengan tujuan praktikum antara kelas kontrol dan eksperimen berbeda signifikan, rerata kelas eksperimen 1,267 sedangkan kelas kontrol 0,833; (7) sig 0,810, kemampuan mengolah data praktikum antara kelas kontrol dan eksperimen tidak berbeda signifikan; (8) sig 0,000, kemampuan membuat kesimpulan praktikum antara kelas kontrol dan eksperimen berbeda signifikan, rerata kelas eksperimen 1,400, kelas kontrol 0,767.

Kedua mengenai kemampuan siswa membuat laporan praktikum yang dijabarkan menjadi empat hipotesis. Hasil ujinya adalah sebagai berikut (1) sig 0,513, bentuk laporan praktikum antara kelas kontrol dan kelas eksperimen tidak berbeda signifikan; (2) sig 0,812 kemampuan menyajikan data dalam laporan praktikum antara kelas kontrol dan kelas eksperimen tidak berbeda signifikan; (3) sig $0,747 \mathrm{sig}>0,05$, kemampuan melakukan pembahasan hasil dalam laporan praktikum antara kelas kontrol dan kelas eksperimen tidak berbeda signifikan; dan (4) sig 0,039, kemampuan menyimpulkan dalam laporan praktikum antara kelas kontrol dengan kelas eksperimen berbeda signifikan, rerata kelas eksperimen sebesar 2,50 dan kelas kontrol 2,03.

Jika dilihat dari pembelajaran yang sudah dilakukan pada proses pengambilan data penelitian, dapat dinyatakan bahwa pendekatan PLE seperti yang sudah dibahas dalam kajian teori belum dapat dilaksanakan secara tepat dan maksimal. Siswa belum sepenuhnya mempergunakan internet untuk menciptakan lingkungan belajar yang benar-benar personal sesuai dengan dirinya sehingga belum bisa memaksimalkan potensi siswa.

Dalam setting pembelajaran pada penelitian ini, internet baru sebatas referensi yang belum bisa menjadi acuan pokok membangun konsep siswa secara mandiri. Sebab secara teori seharusnya siswa harus merancang praktikumnya sendiri sejak awal berdasarkan hasil eksplorasinya menggunakan sumber materi yang berasal internet atau berbagai aplikasi, menentukan alat maupun bahan praktikum sesuai dengan hasil kreativitasnya, dan melakukan percobaan juga secara mandiri, hingga akhirnya dapat menuliskan hasil percobaan dan mempublikasikannya di internet. Hal fundamental lain dalam PLE yang belum sempat dilakukan adalah mengkomunikasikan hasil praktikum yang berupa laporan praktikum dalam blog atau social media yang memungkinkan untuk dapat diakses secara luas dan melihat feedback yang diberikan pengguna media sebagai respon atas hasil kerja siswa. Namun penelitian ini baru sebatas melihat pengaruh pendekatan PLE pada keterampilan siswa untuk membuat laporan praktikum. 


\section{SIMPULAN}

Dari implementasi pendekatan PLE pada praktikum fisika sebagai salah satu cara untuk meningkatkan kemandirian dan kemampuan dalam melaksanakan praktikum fisika pada siswa SMA, dapat disimpulkan bahwa pendekatan PLE tidak mempengaruhi kemampuan siswa merangkai alat praktikum, mengenali alat praktikum, merumuskan tujuan praktikum, menuliskan dasar teori penunjang, dan mengolah data praktikum. Tapi berpengaruh pada kemampuan siswa untuk mengambil data praktikum (dalam penelitian ini menentukan fokus lensa cembung), menyesuaikan dasar teori penunjang dengan tujuan praktikum. dan menyusun kesimpulan praktikum.

Sedangkan dalam kaitannya untuk meningkatkan keterampilan membuat laporan praktikum fisika dapat disimpulkan bahwa: pendekatan PLE tidak mempengaruhi bentuk laporan hasil praktikum siswa, kemampuan siswa menyajikan hasil praktikum pada laporan resmi (tabulasi data), dan kemampuan siswa membuat pembahasan pada laporan praktikum. Tapi mempengaruhi pembuatan kesimpulan laporan praktikum.

\section{REFERENSI}

A.Giambattista, B.M Richardson and R.C Richardson, 2010, Physics, The McGraw-Hill Companies, Inc.

D. Halliday and R. Resnick, J.Walker, 2010, Fisika Dasar Edisi 7. Erlangga.

Dicke JSH Siregar, 2010, Personal Learning Environtments, Majalah Ilmiah IC Tech, vol 5 No 1 Januari.

H.D. Young and R.A. Freedman, 2010, Fisika Universitas Jilid 2. Erlangga.

Mark van Harmelen, Personal Learning Environtments, 2006. Websites:http://www.computer.org.

R. Mauliyani,, Hairida, R. Rasmawan, 2014, Penerapan Constructive Feedback pada Pembuatan Laporan Praktikum Kimia SMA Negeri 7 Pontianak, Websites : http://jurnal.untan.ac.id.

S.A Skrabut,, Personal Learning Environments: The Natural Way of Learning. Website : http://www.uwyo.edu/skrabut/docs/aded5050_project.pdf . 